\title{
Modeling of Dynamic Recrystallization Behavior of As-Extruded AM50 Magnesium Alloy during Hot Compression by a Cellular Automaton Method
}

\author{
Dayu Shu ${ }^{1}$, Jing Wang ${ }^{2}$, Menghao Jiang ${ }^{2}$, Gang Chen ${ }^{2}$, Liwei Lu ${ }^{3}$ and Hongming Zhang ${ }^{4, *}$ \\ 1 Southwest Technology and Engineering Research Institute, Chongqing 400039, China; shudayu1980@163.com \\ 2 School of Materials Science and Engineering, Harbin Institute of Technology, Weihai 264209, China; \\ hitwangj@163.com (J.W.); jiangmhbg@163.com (M.J.); gangchen@hit.edu.cn (G.C.) \\ 3 School of Materials Science and Engineering, Hunan University of Science and Technology, \\ Xiangtan 411201, China; cqullw@163.com \\ 4 School of Ocean Engineering, Harbin Institute of Technology, Weihai 264209, China \\ * Correspondence: zhanghongming@hit.edu.cn; Tel.: +86-133-6119-3703; Fax: +86-0631-568-7931
}

check for updates

Citation: Shu, D.; Wang, J.; Jiang, M.; Chen, G.; Lu, L.; Zhang, H. Modeling of Dynamic Recrystallization

Behavior of As-Extruded AM50

Magnesium Alloy during Hot

Compression by a Cellular

Automaton Method. Metals 2021, 11,

75. https://doi.org/10.3390/met11 010075

Received: 14 November 2020 Accepted: 28 December 2020 Published: 1 January 2021

Publisher's Note: MDPI stays neutral with regard to jurisdictional clai$\mathrm{ms}$ in published maps and institutional affiliations.

Copyright: (C) 2021 by the authors. Licensee MDPI, Basel, Switzerland. This article is an open access article distributed under the terms and conditions of the Creative Commons Attribution (CC BY) license (https:// creativecommons.org/licenses/by/ $4.0 /)$.

\begin{abstract}
The dynamic recrystallization (DRX) behavior of as-extruded AM50 magnesium alloy was modelled and simulated by a cellular automaton (CA) method. Isothermal compression experiments were conducted, and the characteristic parameters in the CA model were obtained by the testing stressstrain flow curves in a wide temperature range of $250-450{ }^{\circ} \mathrm{C}$ and strain rate range of $0.001-10 \mathrm{~s}^{-1}$. The flow stress, DRX volume fraction and DRX grain size of the as-extruded AM50 magnesium alloy were predicted by CA simulation. The results showed that the DRX behavior of the studied magnesium alloy was susceptive with the temperature and strain rate; meanwhile, the prediction results were approximate to the experimental values, indicating that the developed CA model can make a confident estimation on the DRX behavior of the as-extruded AM50 magnesium alloy in high temperature conditions.
\end{abstract}

Keywords: AM50 magnesium alloy; hot compression; dynamic recrystallization; microstructure evolution; cellular automaton

\section{Introduction}

The application of light alloys and their composites is considered as an important lightweight way in advanced industrial fields (e.g., automobile, aerospace and electronics) [1-4]. Recently, magnesium alloys have been given increasing attention due to their high strengths and low densities $\left(\approx 1.8 \mathrm{~g} / \mathrm{cm}^{3}\right)$ [5-7]. An important method for fabricating magnesium parts is plastic deformation. In general, magnesium alloys are considered to be unviable in room-temperature plastic deformation due to the poor ductility. A main cause is that the cross-slip of dislocations are difficult to proceed in the hexagonal crystal structures (HCP) with low-level stacking fault energies of magnesium alloys [8]. Thermoplastic deformation is a commonly acceptable method for the plastic forming of magnesium alloys. The dynamic recrystallization (DRX) plays an important role in the microstructure refinement during thermoplastic deformation of magnesium alloys [9]. Furthermore, it can remarkably impact the mechanical performances according the Hall-Petch relationship [10-12].

Simulation methods are expansively used in studying the microstructure evolution during plastic deformation [13-16]. Particularly, cellular automaton (CA) is a preferred method due to its precise physical meaning and efficient algorithm rule. The CA simulating method was used by Goetz to predict the DRX behavior [17]. Li et al. investigated the microstructural evolution of AZ80 magnesium alloy by CA model coupled with finite element simulation [18]. Chen et al. gave a new approach to predict the average DRX grain size of AZ31B magnesium alloy by CA method [19]. 
The CA simulation results from the physical-based recrystallization kinetic model. Common phenomenological models, e.g., modified Avrami type equations, are widely used for describing the DRX behavior of magnesium alloys [20-22]. However, these phenomenological equations are experience-depended (i.e., without physical meanings), and can only be used in some special deformation conditions. As a result, these phenomenological models are difficult to preciously predict the complex microstructure evolution during DRX [23]. In other words, a physical-based DRX model is critical for CA simulations to describe the DRX microstructure.

AM50 Mg alloy is a widely used extruded magnesium alloy with excellent plasticity and fatigue strength compared to those for as-cast ones [24,25]. However, few researches have focused on microstructure evolution during the hot deformation of AM50 Mg alloy. In this work, the DRX behavior of AM50 Mg alloy during hot deformation was investigated by means of the CA method. The accuracy of the model and simulation are verified by experiments. Furthermore, the relationship between the DRX behavior and the deformation conditions for AM50 Mg alloy are discussed.

\section{Materials and Testing Procedure}

The chemical composition of the AM50 Mg alloy ingot in wt. \% is as follows: $5.2 \mathrm{Al}$, $0.32 \mathrm{Mn}, 0.156 \mathrm{Zn}, 0.056 \mathrm{Si}, 0.0012 \mathrm{Cu}, 0.0001 \mathrm{Fe}, 0.0003 \mathrm{Ni}, 0.0005 \mathrm{Be}$ and $\mathrm{Mg}$ for balance. The cylindrical samples, which had a diameter of $8 \mathrm{~mm}$ and length of $12 \mathrm{~mm}$, were machined from an extruded rod along the extrusion direction. Hot compression simulation tests were performed at deformation temperatures of $250,300,350,400,450{ }^{\circ} \mathrm{C}$ and strain rates of $0.001,0.01,0.1,1,10 \mathrm{~s}^{-1}$ by a thermal simulated test machine (Data Sciences International, Inc., St. Paul, MN, USA). The true strain of 0.9 was defined as the maximum deformation in the test. Once the hot compression was completed, the deformed specimens were immediately quenched into water for reserving the microstructures. The hot compression scheme is shown in Figure 1.

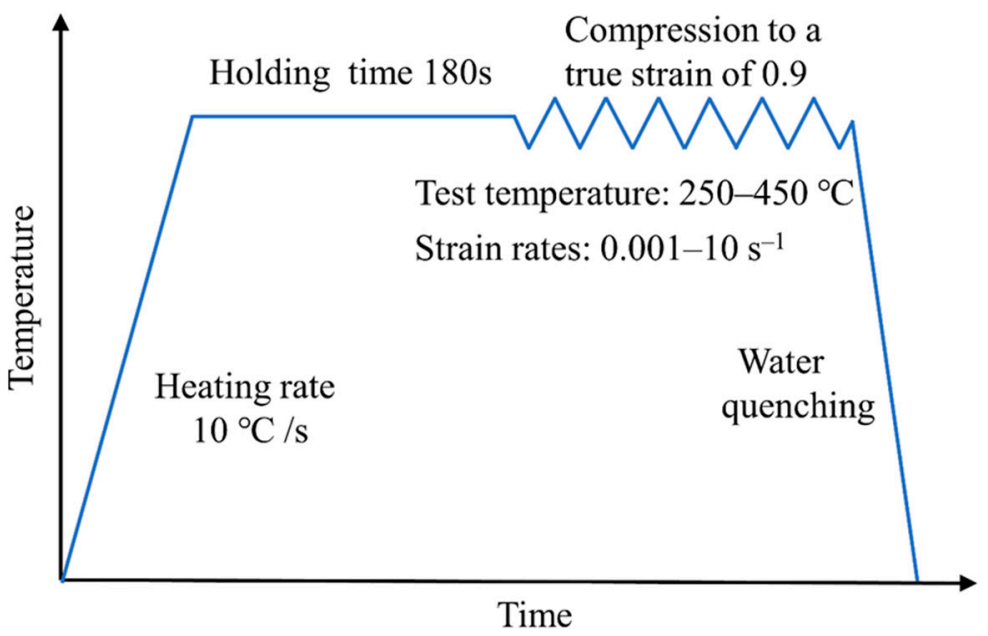

Figure 1. Scheme of the hot compression test.

The specimens were ground and mechanically polished before optical microstructure examinations, and then a solution of picric acid ( $1.5 \mathrm{~g}$, Xinning Pharmaceutical CO., LTD., Taizhou, China) + glacial acetic acid (0.5 g, Xinyue Chemical and Glass CO., LTD., Weihai, China) + ethanol (25 mL, Xinyue Chemical and Glass CO., LTD., Weihai, China) + water $(10 \mathrm{~mL})$ was used to etch the specimens for $60 \mathrm{~s}$. The microstructures were examined by an optical microscope (Olympus Corporation, Tokyo, Japan). Figure 2 shows the initial microstructure of the as-extruded AM50 alloy. The grain size was measured to be approximately $13.6 \mu \mathrm{m}$, along with a few gas porosities to be detected. 


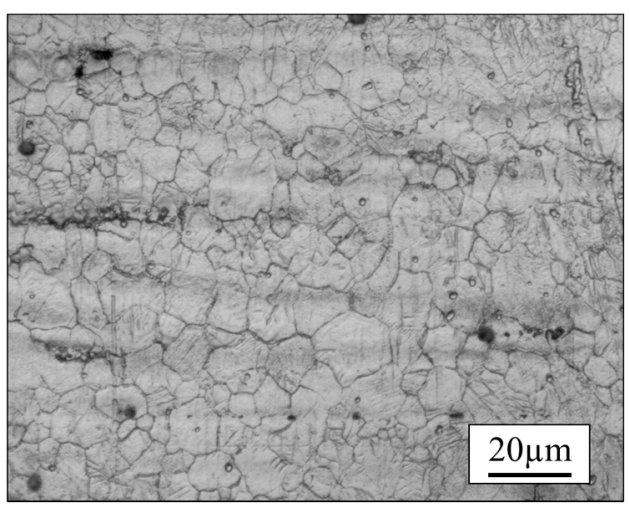

Figure 2. Initial microstructure of the as-extruded AM50 Mg alloy.

\section{Model Description}

The thermoplastic deformation behavior of alloys can be understood as a counteraction between work-hardening and the dynamic softening. Furthermore, the microstructure evolution is a coaction of the multiplication and annihilation of dislocation. Considering these physical relations, a CA model depends on the time and dimension discretization as well as transformation rule for neighboring cells to simulate the microstructure dynamic evolution.

\subsection{Evolution Modeling of Dislocation Density}

In this work, the evolution of dislocation density is modelled as follows [26]:

$$
\frac{\mathrm{d} \rho}{\mathrm{d} \varepsilon}=K_{1} \sqrt{\rho}-K_{2} \rho
$$

where $\rho$ is the dislocation density. The right side of Equation (1) represents the interaction effect of work-hardening and dynamic recovery on the dislocation density. $K_{1}$ and $K_{2}$ are constant parameters that are associated with work-hardening and dynamic recovery, respectively. $K_{1}$ can be determined by $2 \theta /(\theta \alpha \mu b)$ and $K_{2}$ can be determined by $2 \theta / \sigma_{\text {sat }}$ [27]. $\theta$ is the work-hardening rate. $\sigma_{\text {sat }}$ is the saturation stress.

Furthermore, the relationship between flow stress and dislocation density can be represented as following [28]:

$$
\sigma=a \mu b \sqrt{\rho}
$$

where $a$ is the material constant, which can be commonly regarded as the value of 0.5 . $\mu$ is the shear modulus. $b$ is the Burger's vector.

\subsection{Nucleation}

Ding [29] proposed that the rate of nucleation on the grain boundary obeys the following functional relation:

$$
\dot{n}(\dot{\varepsilon}, T)=C \dot{\varepsilon}^{m} \exp \left(-\frac{Q_{a c t}}{R T}\right)
$$

where $C$ and $m$ are material constants. $Q_{a c t}$ is the activation energy.

According to Roberts and Ahlbom [30], the criterion for the occurrence of DRX is the critical dislocation density $\left(\rho_{c}\right)$ exceed threshold, and $\rho_{\mathcal{c}}$ is represented as:

$$
\rho_{c}=\left(\frac{20 \gamma_{i} \dot{\varepsilon}}{3 M b l \tau^{2}}\right)^{1 / 3}
$$

where $\gamma_{i}$ is the grain boundary energy. $\tau$ is average dislocation line energy which can be obtained by $\tau=\alpha \mu b^{2} . l$ is the free dislocation path which can be calculated by $l=10 \mu b / \sigma_{s}$. 
$\sigma_{S}$ is the steady state stress, and $M$ is the grain boundary mobility which can be calculated as follows:

$$
M=\frac{b \delta D_{0 b}}{k T} \exp \left(-\frac{Q_{b}}{R T}\right)
$$

where $\delta$ is the grain boundary thickness. $D_{0 b}$ is the diffusion coefficient of the migrated grain boundary. $Q_{b}$ is the diffusion activation energy, and $k$ is the Boltzmann constant.

The grain boundary energy $\gamma_{i}$ is calculated as follows [31]:

$$
\gamma_{i}= \begin{cases}\gamma_{m} \frac{\theta_{i}}{\theta_{m}}\left(1-\ln \frac{\theta_{i}}{\theta_{m}}\right) & \theta_{i} \leq \theta_{m} \\ \gamma_{m} & \theta_{i}>\theta_{m}\end{cases}
$$

where $\theta_{i}$ is the misorientation of grain boundary. $\theta_{m}$ is grain high angle boundary misorientation (set as $\left.15^{\circ}\right), \gamma_{m}$ is the grain boundary energy of high-angle boundary, which is expressed as [30]:

$$
\gamma_{m}=\frac{\mu b \theta_{m}}{4 \pi(1-v)}
$$

where $v$ is the Poisson's ratio.

\subsection{Grain Growth}

The driving force of grain growth derives from the dislocation density difference between DRX grains and original grains. The relationship between the growth velocity of recrystallized grain boundary $\left(v_{i}\right)$ and the driving force on the grain boundary per cell area $\left(f_{i}\right)$ can be expressed as [32]:

$$
v_{i}=M f_{i}
$$

In this work, the geometrical shape of DRX grain is considered to be spherical, and the $f_{i}$ is calculated as [33]:

$$
f_{i}=\tau\left(\rho_{m}-\rho_{i}\right)-2 \gamma_{i} / r_{i}
$$

where $\rho_{m}$ is the matrix dislocation density. $\rho_{i}$ is the dislocation density of the $i$ th recrystallized grain, and $r_{i}$ is the radius of the $i$ th recrystallized grain.

\section{Simulation Procedures}

\subsection{Cell Dimension Model and State Variable Setting}

A two-dimensional CA program code was developed according to the models of dislocation density evolution, nucleation and grain growth. The area of CA model is defined as $150 \mu \mathrm{m} \times 150 \mu \mathrm{m}$ to predict the DRX behavior of the AM50 alloy. The length of quadrangular cell is $0.2 \mu \mathrm{m}$ and the neighboring transforming rule is Von Neumann type. In the CA model, each cell has five state-variables, including: 1 . the dislocation density variable which is initially set to be $1 \times 10^{11} \mathrm{~m}^{-2}$ uniformly; 2 . the orientation variable which has a random value within the limits of $0-180 ; 3$. the migrating distance variable which controls the growth distance in each iteration step; 4 . the recrystallization number variable which records the DRX number of times; and 5. the grain boundary symbol variable which is used to validate the grain boundary through two figure marking.

\subsection{CA Performing Formulation}

In the CA model, some assumptions are used to improve the simulation efficiency. For instance, the gradient of dislocation density in a grain is neglectful, and the DRX nucleation only occurs on the initial grain boundary and DRX grain boundary. Then, the time in each iteration $(\Delta t)$ is calculated as following [34]:

$$
\Delta t=\frac{L_{c}}{v_{\max }}
$$

where $L_{c}$ is the cell length and $v_{\max }$ is the maximum moving velocity of grain boundaries. 
The strain increment is expressed as $\Delta \varepsilon=\dot{\varepsilon} \Delta t$. In each simulating iteration, the DRX evolution complies with the transformation rules of the state variables, and these state variables are renovated according to the calculated results. The results of CA simulation such as flow stress $(\sigma)$, DRX volume fraction $\left(X_{D R X}\right)$ and average grain size $\left(d_{\text {average }}\right)$ are calculated as follows $[19,35]$ :

$$
\begin{gathered}
\sigma=\alpha \mu b\left(\frac{1}{N_{0}} \sum_{i, j}^{i=A_{1}, j=B_{1}} \rho_{i, j}\right) \\
X_{D R X}=\frac{N_{D R X}}{N_{\text {gain }}} \\
d_{\text {average }}=\sum_{i=1}^{N_{\text {gain }}} d_{i} \frac{S_{i}}{S}
\end{gathered}
$$

where $N_{0}$ is the amounts of the cells. $A_{1}$ and $B_{1}$ are the amounts of cells in $i$ and $j$ direction, respectively. $\rho_{i, j}$ is the dislocation density for the cell in $(i, j)$ coordinates. $N_{\text {gian }}$ is the amounts of total cells and $N_{D R X}$ is the amounts of DRX cells. $S$ is the overall areas of total cells and $S_{i}$ is the area of the $i$ th grain. $d_{i}$ is the diameter of the $i$ th gain, which can be calculated as:

$$
d_{i}=2 \sqrt{\frac{N_{C} S_{C}}{\pi}}
$$

where $N_{C}$ is the number of cells occupied by the grain, $S_{C}$ is the area of a cell.

\subsection{Material Parameters of CA Simulation}

The value of deformation activation energy $Q_{a c t}$ in the CA model was obtained by the flow stress curves of the as-extruded AM50 alloy. The flow stress $\sigma$ is represented as follows [36]:

$$
\dot{\varepsilon}=A[\sinh (\alpha \sigma)]^{n} \exp \left(-Q_{a c t} / R T\right)
$$

where $n, \alpha$ and $A$ are the material constants, respectively. $R$ is the gas constant of $8.314 \mathrm{~J} \mathrm{~mol}^{-1} \mathrm{~K}^{-1}$. $\dot{\varepsilon}$ is strain rate $\left(\mathrm{s}^{-1}\right)$, and $T$ is temperature $(\mathrm{K})$. Taking the natural logarithm of both sides of Equation (15), the expression is re-expressed as follows:

$$
\ln \dot{\varepsilon}=\ln A+\left(-Q_{a c t} / R T\right)+n \ln [\sinh (\alpha \sigma)]
$$

Moreover, $Q_{\text {act }}$ can be expressed as:

$$
Q_{a c t}=n R \frac{\partial \ln \sinh (\alpha \sigma)}{\partial(1 / T)}
$$

$\alpha$ can be represented as the following equation:

$$
\alpha=\left(\frac{\partial \ln \dot{\varepsilon}}{\partial \sigma}\right) /\left(\frac{\partial \ln \dot{\varepsilon}}{\partial \ln \sigma}\right)
$$

In this study, the value of $\sigma$ is considered as $\sigma_{p}$ [37], and linear regression analysis is conducted on the data of $\ln \dot{\varepsilon}-\ln \sigma_{p}, \ln \dot{\varepsilon}-\sigma_{p}, \ln \dot{\varepsilon}-\ln \left(\sinh \left(\alpha \sigma_{p}\right)\right)$ and $\ln \left(\sinh \left(\alpha \sigma_{p}\right)\right)-$ $1 / T$ as shown in the Figure 3. According to the results of Equations (17), (18) and the regression analysis, the value of $Q_{a c t}$ can be calculated to be $130.845 \mathrm{~kJ} \mathrm{~mol}^{-1}$. 
(a)
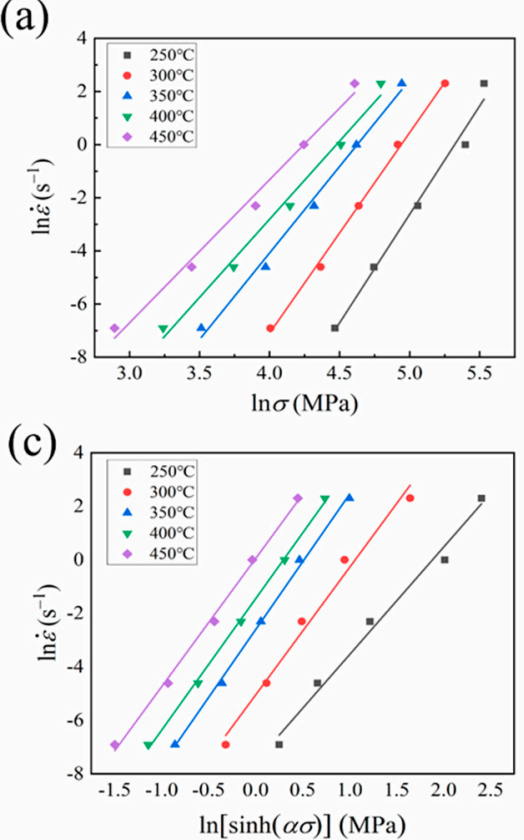

(b)

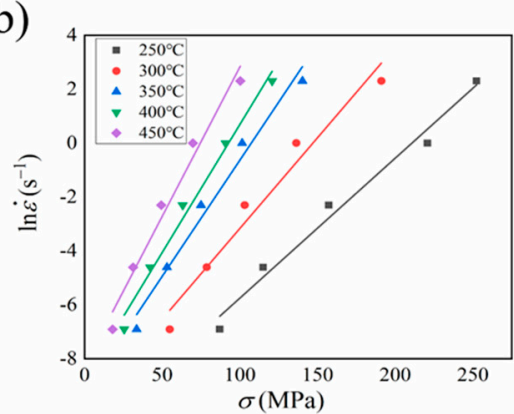

(d)

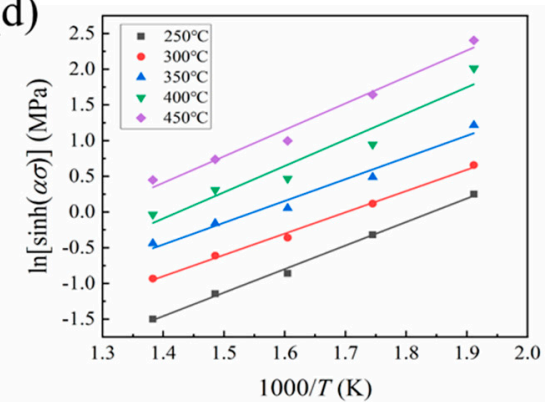

Figure 3. Linear relation of (a) $\ln \dot{\varepsilon}$ versus $\ln \sigma_{p}$, (b) $\ln \dot{\varepsilon}$ versus $\sigma_{p}$, (c) $\ln \dot{\varepsilon}$ versus $\ln \left[\sinh \left(\alpha \sigma_{p}\right)\right]$ and (d) $\ln \left[\sinh \left(\alpha \sigma_{p}\right)\right]$ versus $1000 / T$.

The Zener-Hollomon parameter $(Z)$ is commonly used to combine the effects of strain rate and temperature on the hot deformation [38]. It can be presented as follows:

$$
Z=\dot{\varepsilon} \exp \left(\frac{Q_{a c t}}{R T}\right)
$$

The correlation analysis of the values of $K_{1}$ and $K_{2}$ on the $Z$ parameter are shown in Figure 4 . The results indicate that $\ln K_{1}$ and $\ln K_{2}$ are remarkably linear relative with $\ln Z$.

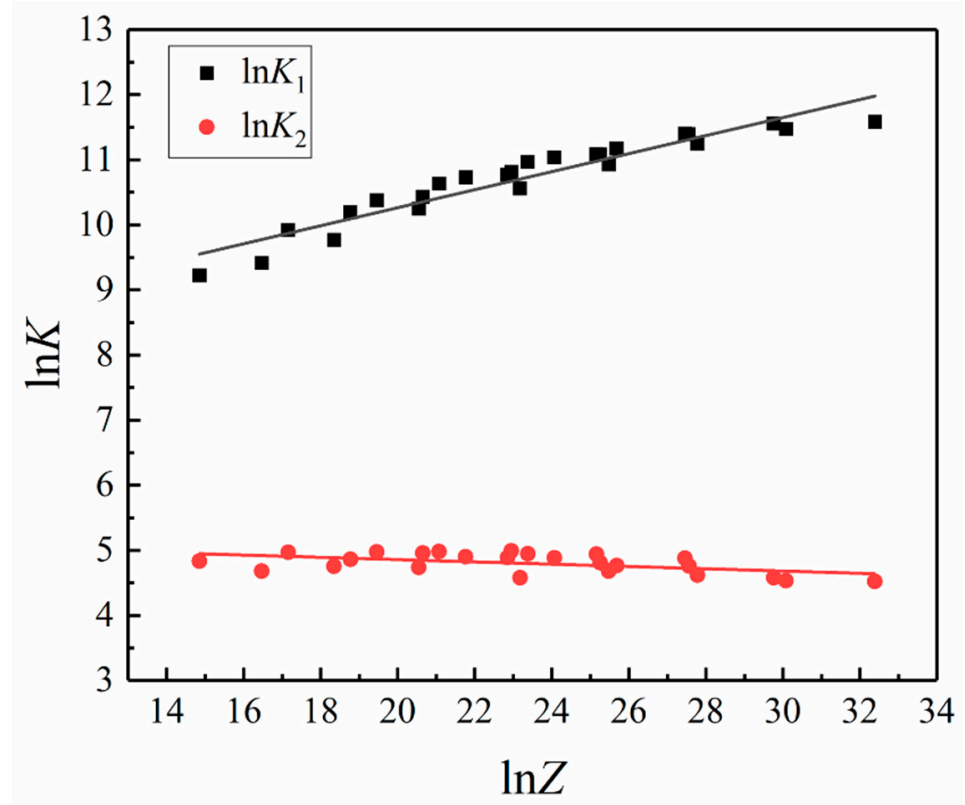

Figure 4. Linear relationships between $\ln K_{i}$ and $\ln Z$.

And then, $K_{1}$ and $K_{2}$ can be expressed by $Z$ as follows:

$$
K_{1}=1.797 \times 10^{3} Z^{0.138}
$$




$$
K_{2}=1.829 \times 10^{2} Z^{-0.018}
$$

In addition, comparing with experimentally measured DRX grain size at certain deformation conditions, some inaccessible material parameters can be determined by iteratively refinement in the CA simulation, and the final values are shown in Table 1. Remarkably, the optimized value of $Q_{b}$ is approximate to the value of experimental diffusion activation energy [39].

Table 1. Obtained appropriate values of material parameters in the simulation.

\begin{tabular}{|c|c|c|c|c|c|c|}
\hline$Q_{b} / \mathrm{kJ} \mathrm{mol}^{-1}$ & $\mu / \mathrm{MPa}$ & $b / \mathrm{m}$ & $\delta D_{0 b} / \mathrm{m}^{3} \mathrm{~s}^{-1}$ & $m$ & $C$ & $v$ \\
\hline 145.425 & 175,000 & $3.2 \times 10^{-10}$ & $\begin{array}{c}1 \times \\
10^{-13}\end{array}$ & 0.75 & $1.2 \times 10^{10}$ & 0.32 \\
\hline
\end{tabular}

\section{Results and Discussion}

The flow stress of the AM50 alloy under different deformation conditions are calculated by Equation (11) using the dislocation density outputs by the CA simulation. Figure 5 shows the comparisons of the flow stress between the CA predicting results and experimental results in the temperature ranges of $250-450{ }^{\circ} \mathrm{C}$ and the strain rate ranges of $0.001-10$ $\mathrm{s}^{-1}$. The results reflect that the simulated results of flow stress are well agreement with the experimental results. Moreover, the stress increases obviously at the beginning of the deformation and subsequently decreases to a stable stage after the stress peak. It indicates the occurrence of the DRX. Moreover, as shown in Figure 6, the maximum relative error (R) is calculated to be 0.99483 .

(a)
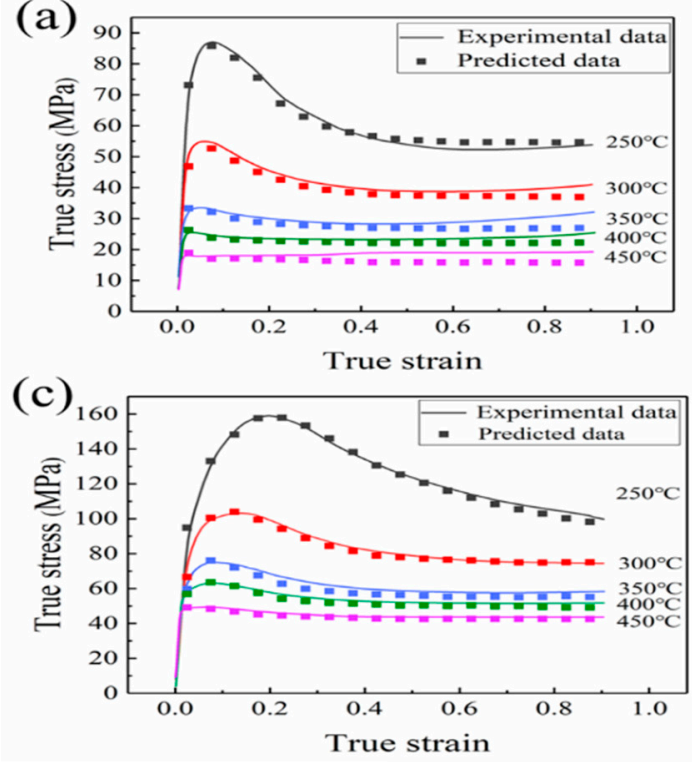

(b)

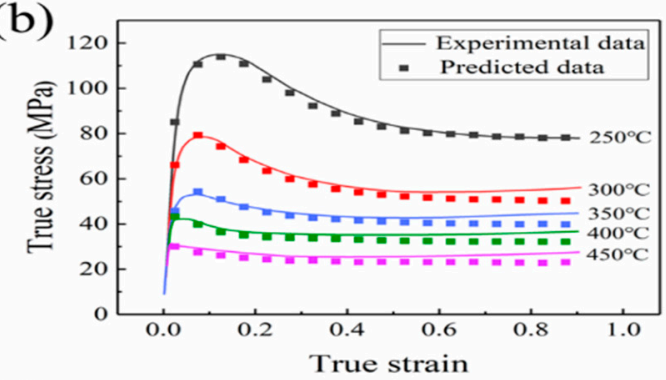

(d)

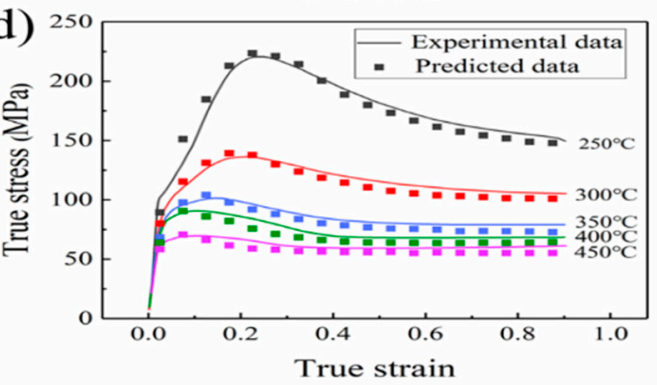

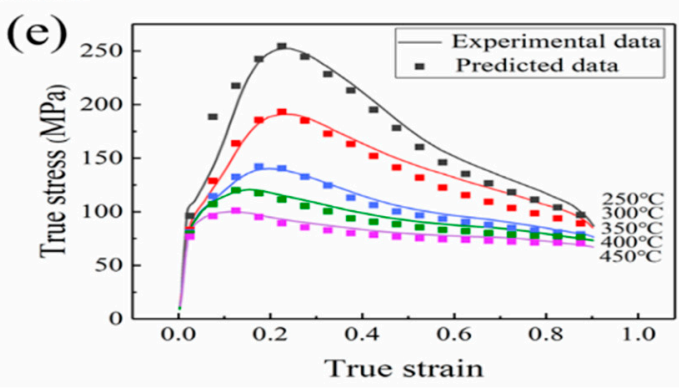

Figure 5. Comparisons between the predicted and measured flow stresses at different strain rates of (a) 0.001 , (b) 0.01 , (c) $0.1,(\mathbf{d}) 1$ and (e) $10 \mathrm{~s}^{-1}$. 


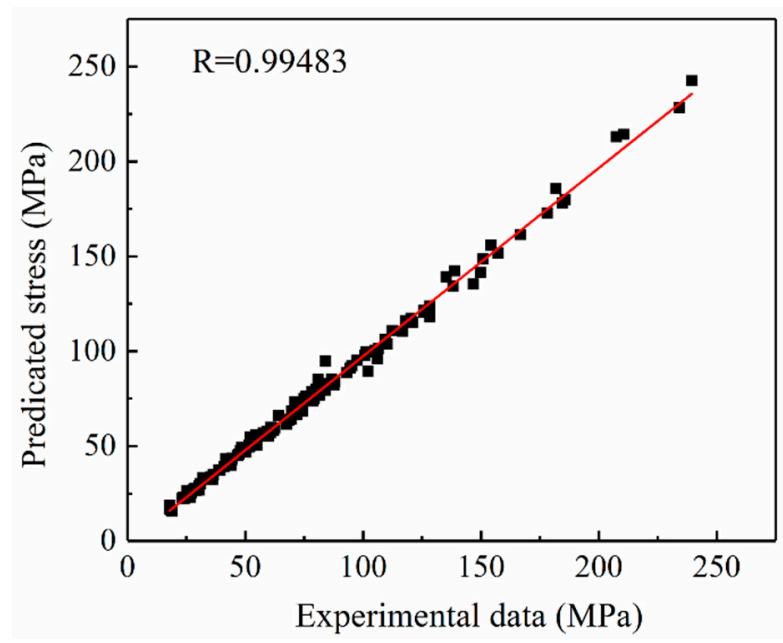

Figure 6. Correlation between the predicted and experimental flow stress results.

The DRX volume fraction of the as-extruded AM50 alloy can also be simulated by CA. To verify the accuracy of the predicted results of the DRX fraction, experimental values are also obtained as [40]:

$$
X_{D R X}=\frac{\sigma_{P}-\sigma}{\sigma_{P}-\sigma_{S S}}
$$

where, $\sigma_{p}$ is the peak stress and $\sigma_{S S}$ is steady stress. Figure 7 shows the volume fraction of DRX by CA-prediction under different strain rates and temperatures, which indicated that the CA-predicted DRX volume fraction results are well matched with the experimental results. Moreover, the DRX fraction curves of the AM50 alloy in Figure 7 show as an "S" like shape. It demonstrates that the dynamic recovery dominates at the beginning of hot deformation. As the deformation proceeded, the dislocations were accumulated and gave adequate motivations for the DRX. Therefore, the DRX volume fraction increased rapidly. With the development of DRX, a balance between the dynamic softening and work-hardening can be finally obtained, corresponding to the steady stages of the DRX fraction curves.

(a)

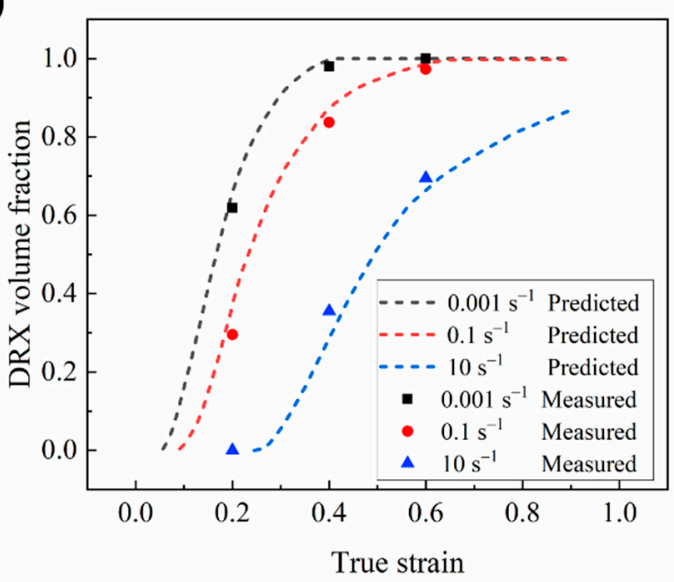

(b)

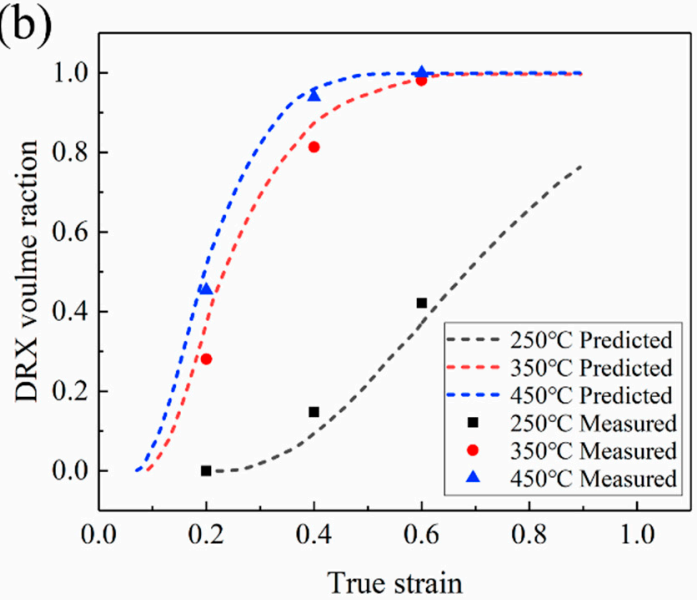

Figure 7. Comparisons between the predicted and measured DRX volume fraction under different deformation conditions of: (a) $350{ }^{\circ} \mathrm{C}$ and (b) $0.1 \mathrm{~s}^{-1}$.

Figure 8 shows the simulations of the microstructural evolution with different strains $\left(350{ }^{\circ} \mathrm{C}, 0.1 \mathrm{~s}^{-1}\right)$ of $0.1,0.2,0.5$ and 0.9 , respectively. According to Figure $8 \mathrm{a}$, few DRX grains are obtained at the strain of 0.1 . It can be attributed to that the grain-inside dislocation density is below the critical dislocation density for DRX. When the strain was 0.2 (Figure 8b), DRX nucleation occurred at the grain boundaries, and recrystallization grains are found. 
In Figure 8c, when the strain increased to 0.5 , the accumulated distortion energy was further promoted, thus the DRX nucleation as well as the DRX volume fraction increased obviously. According to Figure 8d, when the strain was 0.9, all the original grains had been replaced by DRX grains. The results indicate that elevating the strain in the hot deformation is significant for the DRX of AM50 Mg alloy, thus giving fine microstructures.
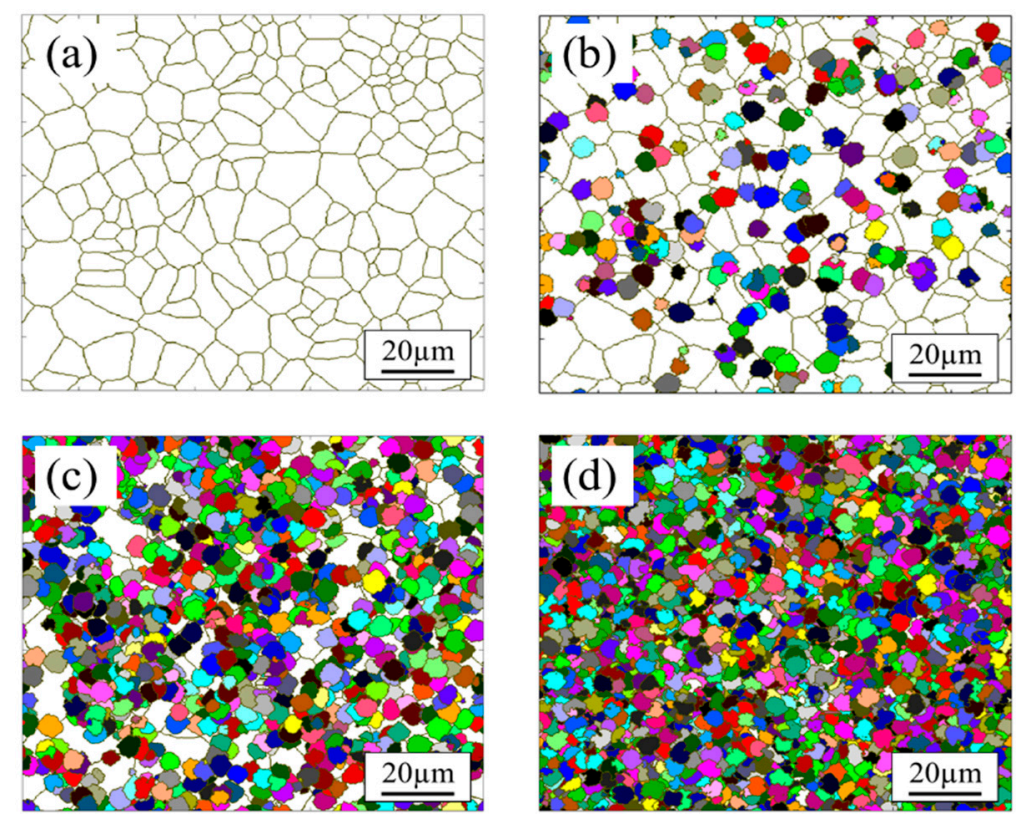

Figure 8. Microstructural evolution under different strains of (a) 0.1 , (b) 0.2 , (c) 0.5 and (d) 0.9 in CA simulation.

Figure 9 shows the experiment and simulated microstructure of AM50 Mg alloy under different strain rates (with a temperature of $350{ }^{\circ} \mathrm{C}$ and a true strain of 0.9 ). The results indicate that the CA simulation results can be used to predict the microstructural morphologies of AM50 Mg alloy under large thermoplastic deformation. According to Figure 9a,d, although fine DRX grains can be obtained, numerous of original grains remained under a strain rate of $10 \mathrm{~s}^{-1}$. Under a strain rate of $0.1 \mathrm{~s}^{-1}$, fine and homogeneously distributed grains are obtained, along with a completely elimination of original grains, as shown in Figure $9 b$,e. According to Figure $9 c, f$, under a strain rate of $0.001 s^{-1}$, although the DRX proceeds completely, the DRX grains is obviously coarser than that under a strain rate of $0.1 \mathrm{~s}^{-1}$. The difference of microstructure evolution under different strain rates is attributed to that a longer deformation period is given under a low strain rate. In this case, the grain boundary migrations are improved, resulting in a high growth rate of the DRX grains [41].

Figure 10 shows the experiment and simulated microstructures at different temperatures of $250{ }^{\circ} \mathrm{C}, 350{ }^{\circ} \mathrm{C}$ and $450{ }^{\circ} \mathrm{C}$ (with a strain rate of $0.01 \mathrm{~s}^{-1}$ and a true strain of 0.9). Figure $10 \mathrm{a}-\mathrm{c}$ show that the DRX grain size is elevated with the increasement of the temperature. In addition, as shown in Figure 10a, deformation twinning can be found at the deformation condition of $250{ }^{\circ} \mathrm{C} / 0.01 \mathrm{~s}^{-1}$. It indicates twin dynamic recrystallization also occurred at low temperature [4]. According to Figure $10 \mathrm{~d}-\mathrm{f}$, the experimental results match the simulation results. It indicates that a high deformation temperature is helpful to give more dislocation energy, thus improving the DRX. Generally, the migration rate of grain boundaries and the growth of DRX grains are positive correlated with the deformation temperature [42]. 

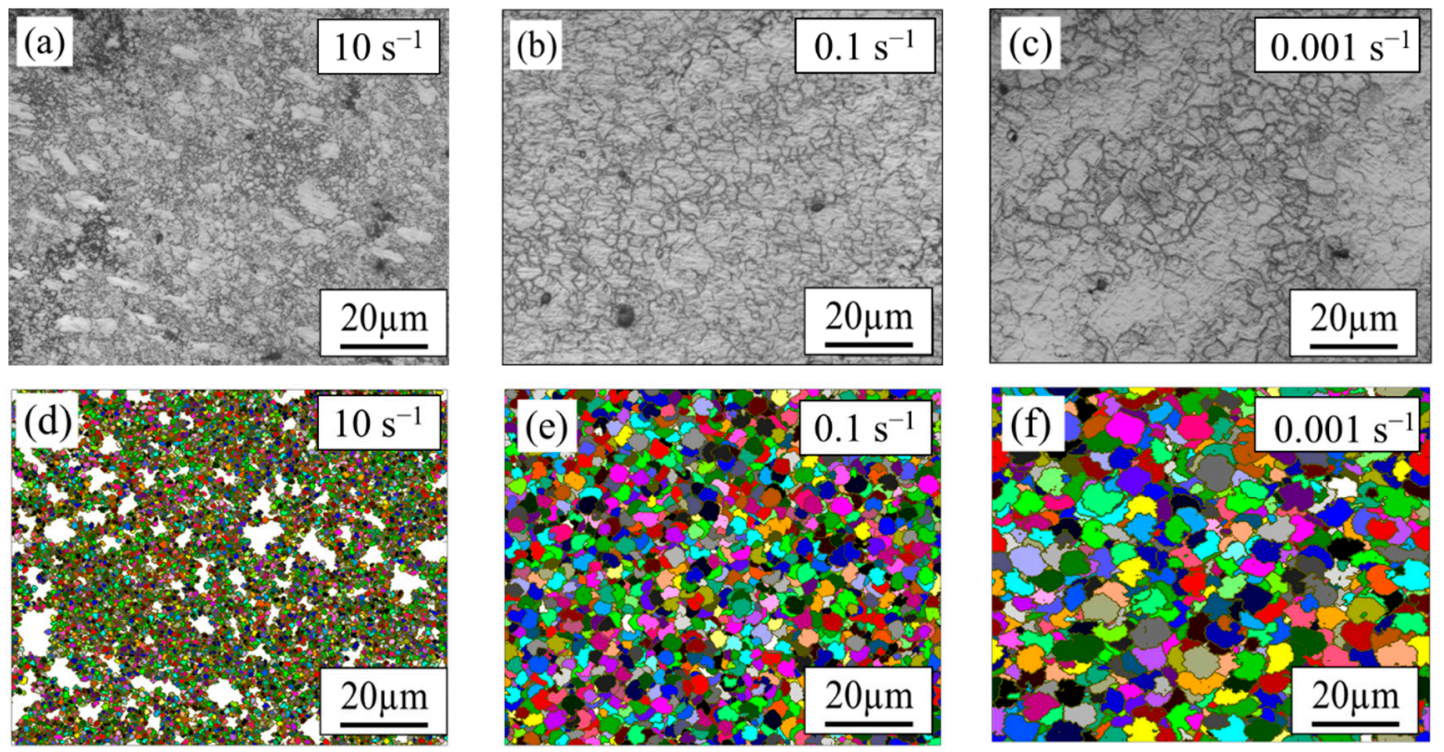

Figure 9. Comparisons between the experiment and the simulated microstructures under different strain rates: (a-c) experiment $(\mathbf{d}-\mathbf{f})$ simulated.
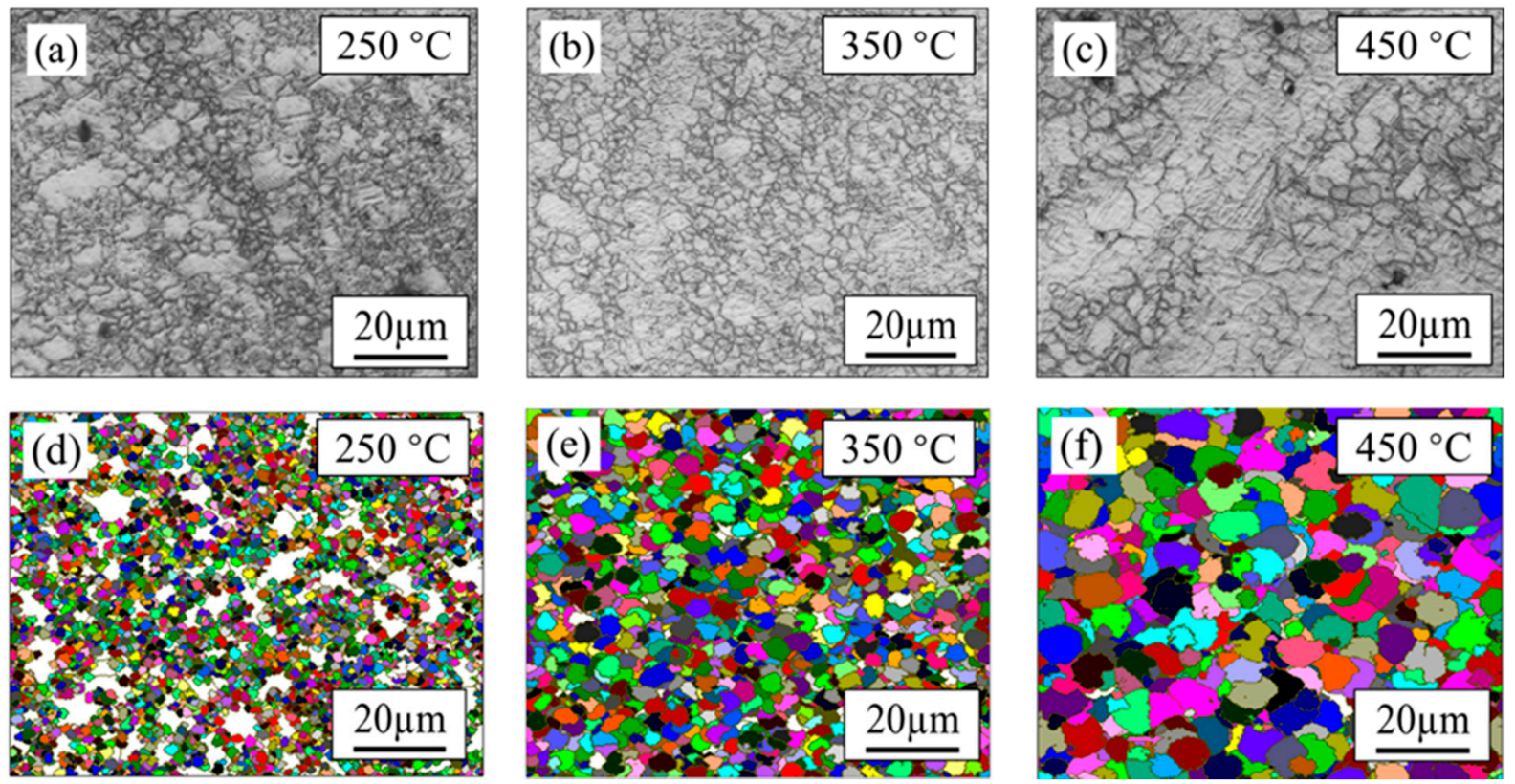

Figure 10. Comparisons between the experiment and simulated microstructures under different temperatures: (a-c) experiment, and (d-f) simulated.

As analyzed above, the DRX grain size of the AM50 Mg alloy is susceptive with the temperature and strain rate. Table 2 gives the comparison on average grain sizes between the experiment and CA simulated microstructures. The maximum relative error is calculated to be $8.82 \%$, indicating the CA simulation is reliable to predict the DRX grain morphology and the grain size of AM50 Mg alloy during hot deformation. 
Table 2. Comparison on the average grain size between the experiment and CA simulated microstructures.

\begin{tabular}{ccccc}
\hline \multirow{2}{*}{ Temperature $/{ }^{\circ} \mathbf{C}$} & Strain Rate/s $\mathbf{s}^{-\mathbf{1}}$ & \multicolumn{2}{c}{ Average Grain Size/ $\boldsymbol{\mu m}$} & \multirow{2}{*}{ Error (\%) } \\
\cline { 3 - 4 } & & Experiment & CA Simulated & \\
\hline 250 & 0.1 & 7.5 & 7.8 & 4.00 \\
350 & 0.001 & 6.6 & 6.4 & 3.03 \\
350 & 0.1 & 5.1 & 4.9 & 3.92 \\
350 & 10 & 6.8 & 6.2 & 8.82 \\
450 & 0.1 & 8.5 & 8.7 & 2.35 \\
\hline
\end{tabular}

\section{Conclusions}

A CA model was proposed for predicting the DRX behavior of AM50 Mg alloy during hot deformation in a wide temperature range of $250-450{ }^{\circ} \mathrm{C}$ and a strain rate range of $0.001-$ $10 \mathrm{~s}^{-1}$. The flow stress, DRX grain size and DRX volume fraction were predicted by the CA simulation. The DRX behavior of the AM50 Mg alloy is susceptive with temperature, strain and strain rate. The grain size can be remarkably refined by the DRX under an appropriate deformation condition. The CA simulated results are well matched with the experiment results, and it demonstrates that the established CA simulation method is appropriate for describing the DRX behavior of AM50 Mg alloy during thermoplastic deformation.

Author Contributions: Investigation, D.S., J.W., and M.J.; Methodology, G.C., and H.Z.; Software, J.W., L.L.; Resources, G.C., and H.Z.; Writing-original draft, D.S.; Writing-review and editing, D.S., and H.Z. All authors have read and agreed to the published version of the manuscript.

Funding: This research was funded by the National Natural Science Foundation of China (Grant Nos. 51875121 and 51905122), Natural Science Foundation of Shandong Province (Grant No. ZR2019MEE039) and Key Research and Development in Shandong Province (Grant No. 2019GGX102046).

Institutional Review Board Statement: Not applicable.

Informed Consent Statement: Not applicable.

Data Availability Statement: The data that support the findings of this study are available from the corresponding author upon reasonable request.

Conflicts of Interest: The authors declare no conflict of interest.

\section{References}

1. Chen, Y.; Hu, L.; Shi, L.X.; Zhou, T.; Tu, J.; Chen, Q.; Yang, M.B. Effect of texture types on microstructure evolution and mechanical properties of AZ31 magnesium alloy undergoing uniaxial tension deformation at room temperature. Mater. Sci. Eng. A 2020, 769, 138497. [CrossRef]

2. Yuan, B.G.; Liu, X.; Du, J.F.; Chen, Q.; Wan, Y.Y.; Xiang, Y.L.; Tang, Y.; Zhang, X.X.; Huang, Z.Y. Effects of hydrogenation temperature on room-temperature compressive properties of CMHT-treated Ti6Al4V alloy. J. Mater. Sci. Technol. 2021, 72, 132-143. [CrossRef]

3. Chen, G.; Chang, X.S.; Zhang, J.X.; Jin, Y.; Sun, C.; Chen, Q. Microstructures and mechanical properties of in-situ $\mathrm{Al}_{3} \mathrm{Ti} / 2024$ aluminum matrix composites fabricated by ultrasonic treatment and subsequent squeeze casting. Met. Mater. Int. 2019, 26, 1574-1584. [CrossRef]

4. Wei, D.X.; Koizumi, Y.; Chiba, A. Discontinuous yielding and microstructural evolution of Ti-40 at \% Al alloy compressed in single $\alpha$-hcp phase region. J. Alloys Compd. 2017, 693, 1261-1276. [CrossRef]

5. Luo, A.A. Magnesium casting technology for structural applications. J. Magnes. Alloy. 2013, 1, 2-22. [CrossRef]

6. Jia, W.; Ma, L.; Tang, Y.; Le, Q.; Fu, L. Relationship between microstructure and properties during multi-pass, variable routes and different initial temperatures hot flat rolling of AZ31B magnesium alloy. Mater. Des. 2016, 103, 171-182. [CrossRef]

7. Wang, Y.; Li, F.; Li, X.W.; Fang, W.B. Unusual texture formation and mechanical property in AZ31 Magnesium Alloy sheets processed by CVCDE. J. Mater. Process. Technol. 2020, 275, 116360. [CrossRef]

8. Park, J.; Kim, J.; Park, N.; Kim, Y. Study of forming limit for rotational incremental sheet forming of magnesium alloy sheet. Metall. Mater. Trans. A 2010, 41,97. [CrossRef]

9. Barrett, C.D.; Imandoust, A.; Oppedal, A.L.; Inal, K.; Tschopp, M.A.; Kadiri, H.E. Effect of grain boundaries on texture formation during dynamic recrystallization of magnesium alloys. Acta Mater. 2017, 128, 270-283. [CrossRef] 
10. Galiyev, A.; Kaibyshev, R.; Gottstein, G. Correlation of plastic deformation and dynamic recrystallization in magnesium alloy ZK60. Acta Mater. 2001, 49, 1199-1207. [CrossRef]

11. Varzaneh, S.M.F.; Hanzaki, A.Z.; Beladi, H. Dynamic recrystallization in AZ31 magnesium alloy. Mater. Sci. Eng. A 2007, 456, 52-57. [CrossRef]

12. Wei, D.X.; Koizumi, Y.; Nagasako, M.; Chiba, A. Refinement of lamellar structures in Ti-Al alloy. Acta Mater. 2017, 125, 81-97. [CrossRef]

13. Radhakrishnan, B.; Gorti, S.B.; Stoica, G.M.; Muralidharan, G.; Stoica, A.D.; Wang, X.L.; Specht, E.D.; Kenik, E.; Muth, T. Mesoscale modeling and validation of texture evolution during asymmetric rolling and static recrystallization of magnesium alloy AZ31B. Metall. Mater. Trans. A 2012, 43, 1509-1516. [CrossRef]

14. Wang, M.; Zong, B.Y.; Wang, G. Grain growth in AZ31 Mg alloy during recrystallization at different temperatures by phase field simulation. Comput. Mater. Sci. 2009, 45, 217-222. [CrossRef]

15. Zhang, H.; Wang, J.; Chen, Q.; Shu, D.Y.; Wang, C.P.; Chen, G.; Zhao, Z.D. Study of dynamic recrystallization behavior of T2 copper in hot working conditions by experiments and cellular automaton method. J. Alloys Compd. 2019, 784, 1071-1083. [CrossRef]

16. Barrett, C.D.; Imandoust, A.; Kadiri, H.E. The effect of rare earth element segregation on grain boundary energy and mobility in magnesium and ensuing texture weakening. Scr. Mater. 2018, 146, 46-50. [CrossRef]

17. Goetz, R.L. Particle stimulated nucleation during dynamic recrystallization using a cellular automata model. Scr. Mater. 2005, 52, 851-856. [CrossRef]

18. Li, X.L.; Li, X.L.; Zhou, H.T.; Zhou, X.; Li, F.B.; Liu, Q. Simulation of dynamic recrystallization in AZ80 magnesium alloy using cellular automaton. Comput. Mater. Sci. 2017, 140, 95-104. [CrossRef]

19. Chen, M.S.; Yuan, W.Q.; Li, H.B.; Zou, Z.H. Modeling and simulation of dynamic recrystallization behaviors of magnesium alloy AZ31B using cellular automaton method. Comput. Mater. Sci. 2017, 136, 163-172. [CrossRef]

20. Lv, B.J.; Peng, J.; Wang, Y.J.; An, X.Q.; Zhong, L.P.; Tang, A.T.; Pan, F.S. Dynamic recrystallization behavior and hot workability of Mg-2.0 Zn-0.3 Zr-0.9 Y alloy by using hot compression test. Mater. Des. 2014, 53, 357-365. [CrossRef]

21. Xu, Y.; Hu, L.; Sun, Y. Deformation behaviour and dynamic recrystallization of AZ61 magnesium alloy. J. Alloys Compd. 2013, 580, 262-269. [CrossRef]

22. Cai, Z.W.; Chen, F.X.; Ma, F.J.; Guo, J.Q. Dynamic recrystallization behavior and hot workability of AZ41M magnesium alloy during hot deformation. J. Alloys Compd. 2016, 670, 55-63. [CrossRef]

23. Sun, F.; Zhang, D.Q.; Cheng, L.; Zheng, P.; Liao, D.M.; Zhu, B. Microstructure evolution modeling and simulation for dynamic recrystallization of $\mathrm{Cr} 12 \mathrm{MoV}$ die steel during hot compression based on real metallographic image. Met. Mater. Int. 2019, 25, 966-981. [CrossRef]

24. Chen, L.; Wang, C.; Wu, W.; Liu, Z.; Stoica, G.M.; Wu, L.; Liaw, P.K. Low-cycle fatigue behavior of an as-extruded AM50 magnesium alloy. Metall. Mater. Trans. A 2007, 38, 2235-2241. [CrossRef]

25. Zhou, M.; Hu, H.; Li, N.; Lo, J. Microstructure and tensile properties of squeeze cast magnesium alloy AM50. J. Mater. Eng. Perform. 2005, 14, 539-545. [CrossRef]

26. Tóth, L.S.; Molinari, A.; Estrin, Y. Strain hardening at large strains as predicted by dislocation based polycrystal plasticity model. J. Eng. Mater. Technol. 2002, 124, 71-77. [CrossRef]

27. Liu, X.; Li, L.X.; He, F.Y.; Zhou, J.; Zhu, B.W.; Zhang, L.Q. Simulation on dynamic recrystallization behavior of AZ31 magnesium alloy using cellular automaton method coupling Laasraoui-Jonas model. Trans. Nonferrous Met. Soc. China 2013, 23, 2692-2699. [CrossRef]

28. Svoboda, A.; Wedberg, D.; Lindgren, L.E. Simulation of metal cutting using a physically based plasticity model. Model. Simul. Mater. Sci. Eng. 2010, 18, 1825-1830. [CrossRef]

29. Ding, R.; Guo, Z.X. Coupled quantitative simulation of microstructural evolution and plastic flow during dynamic recrystallization. Acta Mater. 2001, 49, 3163-3175. [CrossRef]

30. Roberts, W.; Ahlbom, B. A nucleation criterion for dynamic recrystallization during hot working. Acta Metall. 1978, 26, 801-813 [CrossRef]

31. Zhang, C.; Tang, X.; Zhang, L.W.; Cui, Y. Cellular automaton modeling of dynamic recrystallization of Ni-Cr-Mo-based C276 superalloy during hot compression. J. Mater. Res. 2019, 34, 3093-3103. [CrossRef]

32. Wu, H.; Xu, W.; Wang, S.B.; Yang, Z.Z.; Guo, B. A cellular automaton coupled FEA model for hot deformation behavior of AZ61 magnesium alloys. J. Alloys Compd. 2020, 816, 152562. [CrossRef]

33. Wang, L.X.; Fang, G.; Qian, L.Y. Modeling of dynamic recrystallization of magnesium alloy using cellular automata considering initial topology of grains. Mater. Sci. Eng. A 2018, 711, 268-283. [CrossRef]

34. Liu, Y.X.; Lin, Y.C.; Li, H.B.; Wen, D.X.; Chen, X.M.; Chen, M.S. Study of dynamic recrystallization in a Ni-based superalloy by experiments and cellular automaton model. Mater. Sci. Eng. A 2015, 626, 432-440. [CrossRef]

35. Hallberg, H.; Wallin, M.; Ristinmaa, M. Simulation of discontinuous dynamic recrystallization in pure Cu using a probabilistic cellular automaton. Comput. Mater. Sci. 2010, 49, 25-34. [CrossRef]

36. Sellars, C.M.; McTegart, W.J. On the mechanism of hot deformation. Acta Mater. 1966, 14, 1136-1138. [CrossRef]

37. Li, L.; Zhang, X.M. Hot compression deformation behavior and processing parameters of a cast Mg-Gd-Y-Zr alloy. Mater. Sci. Eng. A 2011, 528, 1396-1401. [CrossRef] 
38. Yi, H.L.; Wei, D.X.; Wang, Y.C.; Wang, L.Q.; Fang, M.Y.; Yang, K.; Kato, H. Hot Deformation and Dynamic Recrystallization Behavior of $\mathrm{CoCrNi}$ and $(\mathrm{CoCrNi})_{94} \mathrm{Ti}_{3} \mathrm{Al}_{3}$ Medium Entropy Alloys. Metals 2020, 10, 1341. [CrossRef]

39. Kammerer, C.C.; Kulkarni, N.S.; Warmack, R.J.; Sohn, Y.H. Interdiffusion and impurity diffusion in polycrystalline Mg solid solution with $\mathrm{Al}$ or Zn. J. Alloys Compd. 2014, 617, 968-974. [CrossRef]

40. Xia, Y.N.; Zhang, C.; Zhang, L.W.; Shen, W.F.; Xu, Q.H. A comparative study of constitutive models for flow stress behaviorof medium carbon Cr-Ni-Mo alloyed steel at elevated temperature. J. Mater. Res. 2017, 32, 3875-3884. [CrossRef]

41. Changizian, P.; Zarei-Hanzaki, A.; Roostaei, A.A. The high temperature flow behavior modeling of AZ81 magnesium alloy considering strain effects. Mater. Des. 2012, 39, 384-389. [CrossRef]

42. Chen, X.; Liao, Q.; Niu, Y.; Jia, W.T.; Le, Q.C.; Cheng, C.L.; Yu, F.X.; Cui, J.Z. A constitutive relation of AZ80 magnesium alloy during hot deformation based on Arrhenius and Johnson-Cook model. J. Mater. Res. Technol. 2019, 8, 1859-1869. [CrossRef] 